\title{
Enhancing the Efficiency and Regioselectivity of P450 Oxidation Catalysts via Unnatural Amino Acid Mutagenesis
}

\author{
Joshua N. Kolev, Jacqueline M. Zaengle, Rajesh Ravikumar, and Prof. Rudi Fasan ${ }^{[a]}$ \\ Rudi Fasan: fasan@chem.rochester.edu \\ [a]Department of Chemistry, University of Rochester, Hutchison Hall, Rochester, NY 14620 (USA)
}

\section{Abstract}

The development of effective strategies for modulating the reactivity and selectivity of cytochrome P450 enzymes represents a key step toward expediting the use of these biocatalysts for synthetic applications. In this work, we investigated the potential of unnatural amino acid mutagenesis to aid efforts in this direction. To this end, four unnatural amino acids comprising a diverse set of aromatic side-chain groups were incorporated into eleven active site positions of a substrate-promiscuous CYP102A1 variant. The resulting 'uP450s' were then tested for their catalytic activity and regioselectivity in the oxidation of two representative substrates consisting of a small-molecule drug and a natural product. Large shifts in regioselectivity were obtained as a result of these single mutations and, in particular, via para-acetyl-Phe substitutions at positions in close proximity to the heme cofactor. Notably, screening of this mini library of uP450s enabled the rapid identification of $\mathrm{P} 450$ catalysts for the selective hydroxylation of four aliphatic positions in the target substrates, including a $\mathrm{C}\left(s p^{3}\right)-\mathrm{H}$ site not oxidized by the parent enzyme. Furthermore, our studies led to the discovery of a general activity-enhancing effect of active site substitutions involving the unnatural amino acid para-amino-Phe, resulting in P450 catalysts capable of supporting the highest total turnover number reported to date on a complex molecule (34,650 turnovers). The functional changes induced by the unnatural amino acids could not be recapitulated by any of the twenty natural amino acids. This study thus demonstrates that unnatural amino acid mutagenesis constitutes a promising, new strategy for improving the catalytic activity and regioselectivity of P450 oxidation catalysts.

\section{Keywords}

cytochrome $\mathrm{P} 450$ monoxygenases; selective $\mathrm{C}-\mathrm{H}$ oxidation; unnatural amino acid; protein engineering; terpene

\section{Introduction}

The selective oxidation of aliphatic $\mathrm{C}-\mathrm{H}$ bonds bears enormous potential toward facilitating the construction and manipulation of organic molecules. ${ }^{[1]}$ This transformation is yet notoriously challenged by the inherent strength of these chemical bonds, their

Correspondence to: Rudi Fasan, fasan@chem.rochester.edu.

Supporting information for this article is available on the WWW under http://www.chembiochem.org or from the author. 
widespread occurrence in organic molecules, and the higher reactivity of the oxidized products compared to the starting material. Cytochromes P450 (P450s) comprise a large class of heme-dependent monoxygenase enzymes capable of hydroxylating unactivated aromatic and aliphatic $\mathrm{C}-\mathrm{H}$ bonds using molecular oxygen under very mild conditions. ${ }^{[2]}$ As such, P450s have attracted significant interest as catalytic platforms for mediating the oxidation of organic molecules. ${ }^{[3]}$ Efforts in this area are in large part inspired by the ability of natural $\mathrm{P} 450$ s to execute $\mathrm{C}-\mathrm{H}$ oxidation transformations with exquisite chemo-, regio-, and stereocontrol as part, for example, of the biosynthesis of complex natural products. ${ }^{[4]}$ Achieving the same level of selectivity and catalytic efficiency in the context of non-native substrates has remained however a fundamental challenge. ${ }^{[5]}$ A common strategy for affecting these properties in P450 monooxygenases has involved the use of amino acid mutagenesis, by targeting the entire monoxygenase domain ${ }^{[3 a, 6]}$ or focusing on the enzyme active $\operatorname{site}^{[3 \mathrm{i}, 3 \mathrm{k}, 3 \mathrm{~m}, 7]}$ or both ${ }^{[3 \mathrm{~d}]}$. For example, in combination with fingerprint-based methods for P450 function prediction, active site mutagenesis has been successfully utilized by our group to develop highly regio- and stereoselective P450 catalysts for the late-stage oxyfunctionalization of complex natural products. ${ }^{[3 \mathrm{~m}, 7]}$ Whereas large 'leaps' in P450 function have typically required the combination of multiple 'natural' amino acid substitutions, ${ }^{[3 \mathrm{~m}, 7-8]}$ we reasoned that complementary opportunities in this regard could be provided by exploring the sequence space in an orthogonal direction, i.e. by expanding the number and types of amino acid residues introduced at a given position within the $\mathrm{P} 450$ fold.

Recent methodologies for the ribosomal incorporation of unnatural amino acids has provided a powerful and convenient tool for introducing a variety of non-proteogenic functionalities into recombinant proteins. ${ }^{[9]}$ Over the past few years, unnatural amino acids (UAAs) have been introduced into enzymes for the purpose of studying their function ${ }^{[10]}$ or controlling their activation in a time-resolved manner. ${ }^{[11]}$ Similarly, unnatural amino acids have been utilized in the context of $\mathrm{P} 450$ s to probe the conformational properties or catalytic mechanism of these enzymes. For example, ${ }^{13} \mathrm{C}$-labeled $p$-methoxy-phenyalanine has been introduced in CYP119 to monitor the conformational changes occurring upon substrate binding. ${ }^{[12]}$ Other groups have replaced the heme-ligating cysteine ${ }^{[13]}$ and other conserved residues ${ }^{[14]}$ in $\mathrm{P} 450$ cam to examine the role of these amino acid residues on the catalytic function of the monoxygenase. In contrast, studies directed at modulating the catalytic properties of enzymes via unnatural amino acid mutagenesis have remained scarce, ${ }^{[15]}$ and, with P450 enzymes, only limited to global substitution approaches. ${ }^{[16]}$

The potential of unnatural amino acid mutagenesis toward modulating, and ideally, improving the catalytic and selectivity properties of P450-based oxidation catalysts has thus remained largely unexplored. Toward this goal, we report the successful incorporation of four structurally different aromatic UAAs at multiple positions within the active site of a catalytically self-sufficient, bacterial P450 (CYP102A1). Using two representative target substrates, the relative benefits conferred by this approach with respect to conventional mutagenesis were investigated. Our studies demonstrate the distinctive ability of certain unnatural amino acids to alter P450 reactivity in a way that none of the natural amino acids 
does, enabling the rapid development of P450 catalysts with greatly improved site selectivity and catalytic efficiency properties.

\section{Results and Discussion}

\section{Incorporation of unnatural amino acids in CYP102A1 variant}

The long-chain fatty acid monoxygenase CYP102A1 ( $\left.\mathrm{P} 450_{\mathrm{BM} 3}\right)$ from B. megaterium $^{[17]}$ was chosen as a model system for this study. CYP102A1 has provided an attractive scaffold for the development of P450-based oxidation catalysts, ${ }^{[5,18]}$ especially in view of its high activity (compared to other natural P450s) and its catalytic self-sufficiency as given by its single-component organization (i.e. heme-containing monoxygenase domain is genetically fused to a diflavin reductase ${ }^{[19]}$ ). In particular, an engineered variant of CYP102A1, called 139- $3^{[3 \mathrm{a}]}$, was chosen as the parent enzyme for the incorporation of the target unnatural amino acids. Compared to wild-type CYP102A1, 139-3 contains two mutations within the active site (Val78Ala, Ala184Val), which contribute to expand the volume of the heme pocket by about $30 \AA^{3 .[8]}$ As a result of these mutations and nine additional ones across the heme domain (see SI for details), this P450 exhibits high oxidation activity across a broad range of substrates, which include linear alkanes, ${ }^{[3 \mathrm{a}]}$ terpenes, ${ }^{[8]}$ and synthetic small molecules. ${ }^{[3 \mathrm{f}]}$

Based on the crystal structure of this variant, ${ }^{[8]}$ a total of eleven active site positions were selected for substitution with the unnatural amino acids, namely Ala74, Leu75, Ala78, Phe81, Ala82, Phe87, Leu181, Val184, Leu188, Thr327, and Ala328 (Figure 1A). These sites include amino acid residues that are located in proximity to the heme prosthetic group (e.g. 87, 328) as well as more remote positions (e.g. 184, 188). In addition, the parental residues comprise different apolar side chains, ranging from aromatic (Phe) to branched (Val, Leu) and unbranched aliphatic (Ala) groups.

A wide range of unnatural amino acids have been incorporated into proteins by means of amber stop codon suppression and orthogonal aminoacyl-tRNA synthetase/tRNA pairs in $E$. coli. ${ }^{[9 a]}$ Among these, four target unnatural amino acids were chosen for this study, namely para-amino-phenylalanine $(\mathrm{pAmF})^{[20]}$, para-acetyl-phenylalanine $(\mathrm{pAcF})^{[21]}$, O-benzyltyrosine $(\mathrm{OBnY})^{[22]}$, and 3-(2-naphtyl)-alanine (NapA) ${ }^{[23]}$ (Figure 1B). These structures comprise a diverse set of aromatic side-chain groups, which differ both in overall size (e.g. $\mathrm{pAmF}$ and $\mathrm{pAcF} v s . \mathrm{OBnY}$ and $\mathrm{NapA}$ ) and in the nature and $\mathrm{H}$-bonding properties of the functional group appended to the aromatic ring (e.g. acetyl vs. amino group in pAcF and pAmF, respectively).

To allow for the site-selective incorporation of these UAAs into 139-3, each of the selected active site positions was replaced with an amber stop codon (TAG) in the gene encoding for the P450 enzyme. The corresponding enzyme variants were then expressed in E. coli cells containing the appropriate, engineered Methanococcus jannaschii tyrosyl-tRNA synthetase and cognate amber suppressor tRNA $\mathrm{CUA}_{\mathrm{A}}$ in the presence of the desired UAA. After expression, cells were lysed and the amount of each of the 44 UAA-containing P450 variants ('uP450s') was determined via CO binding assay. The specificity of incorporation for each of the aminoacyl-tRNA synthetases (AARSs) under the applied expression 
conditions was confirmed via control experiments in which no UAA was added to the culture medium, which resulted in no detectable amount of recombinant $\mathrm{P} 450$. The expression yields were then compared to that of the parent enzyme (Figure 2).

As evidenced by these data, half of the desired uP450s (22/44) could be expressed in good to very good yields, i.e. with $10 \%$ to $95 \%$ relative expression yield as compared to the parent enzyme (Figure 2). Additional 12 variants could be obtained in lower but still appreciable amounts, i.e. with yields ranging from 2 to $15 \mathrm{mg}$ protein per liter of culture. Overall, these experiments demonstrated the feasibility of incorporating a diverse set of aromatic UAAs within the active site of a P450.

\section{Dependence of UP450 expression yield on mutagenesis site and type of UAA}

Since the expression yield reflects the degree by which a mutation is tolerated ${ }^{[24]}$, insights into the dependence of this parameter on the position targeted for mutagenesis and the nature of the UAA can be gained from the data of Figure 2. A prerequisite for these analyses, however, is that the expression level of the uP450 is not significantly affected by the relative incorporation efficiency of the respective AARS. Control experiments using a reporter Yellow Fluorescent Protein showed indeed that the poor expression levels of the pAmF-containing uP450s are due to the low activity of the pAmF-RS synthetase (Figure S1). In contrast, the amount of YFP produced with the other AARSs was comparable, with the variation in YFP expression level being considerably lower ( $<15 \%$ std. dev., Figure S1) than the 2- to 10-fold differences observed for the NapA-, OpgY- and pAcF-containing uP450s. These results indicated that the latter can be used to assess the extent by which these substitutions are tolerated by the P450 scaffold.

Accordingly, comparison of the average expression yields across all the eleven active site positions indicated that substitutions with $\mathrm{OBnY}$ are much better tolerated (45\% avg. rel. yield) than those with NapA (11\%) or pAcF (11\%). This trend was somewhat surprising considering the relative large steric bulk associated with the side chain of ObnY as compared to pAcF, suggesting that this feature is not a critical factor in affecting the stability of the resulting uP450. With respect to the site targeted for mutagenesis, all positions except Thr327 were found to be able to accomodate the incorporation of two or more UAAs. The intolerance of the 327 site to introduction of any of the UAAs is likely due a general incompatibility of this site to mutagenesis for structural reasons, as suggested by the fact that only isosteric substitutions (i.e. Thr327Val) have been reported at this site. ${ }^{[18]}$ Interestingly, no correlation was found between the nature of the parental residue and the relative tolerance of the site to UAA mutagenesis. Indeed, the average relative expression yield (across all UAAs expect pAmF) for positions occupied by phenylalanine (18\%) was lower than and comparable to that for positions occupied by branched aliphatic residues (Val or Leu; $31 \%$ ) and Ala (20\%), respectively. Importantly, these results demonstrated that the introduction of aromatic residues of varying size as emcompassed by the set of UAAs investigated here is not restricted to positions occupied by aromatic residues (i.e. F87 and F81). 


\section{Oxidation of (S)-ibuprofen and (+)-nootkatone by parent P450}

From the experiments above, a small library of uP450s was thus made available to examine the effect of UAA mutagenesis on the catalytic and selectivity properties of the enzyme. Two model substrates were selected for this purpose, namely $(S)$-ibuprofen methyl ester (1, Scheme 1) and (+)-nootkatone (2, Scheme 1). These compounds comprise a large number of different $\mathrm{C}-\mathrm{H}$ bonds, including primary, secondary, tertiary, and aromatic $\mathrm{C}-\mathrm{H}$ bonds, as well as various functional groups (carbonyl, ester, olefinic group), making them challenging targets for selective $\mathrm{C}-\mathrm{H}$ bond oxidation. In addition, they differ in size and in structural complexity, providing the opportunity to evaluate the effect of UAA substitutions in the context of a small-molecule drug (1) and a bulkier natural product (2). In addition to its commercial value as a fragrance compound, interest in the late-stage functionalization of $(+)$-nootkatone also stems from its promising activity as an antiproliferative agent ${ }^{[25]}$.

Oxidation of 1 with the parent enzyme 139-3 occurs with poor selectivity, producing a mixture of the benzylic alcohol 3 and tertiary alcohol 4 (Scheme 1) in 62\% and 38\% ratio, respectively. On the other hand, 139-3-catalyzed transformation of 2 favours oxidation of the C11-C12 double bond, resulting in the formation of the epoxide 5 as the largely predominant product (96\%) together with small amounts of the allylic alcohol 6 (4\%). The chosen substrates thus provided ideal test cases to evaluate the potential of UAA mutagenesis toward improving the enzyme regioselectivity in the case of $\mathbf{1}$, and steering such selectivity towards less activated positions (i.e. aliphatic $\mathrm{C}-\mathrm{H}$ bonds) in the case of 2 .

\section{Site-selectivity of uP450s in the oxidation of the target substrates}

Accordingly, the uP450 variants were screened for activity on these substrates via in vitro reactions using P450 from cell lysate in the presence of a NADPH cofactor regeneration system consisting of phosphite and a thermostable phosphite dehydrogenase ${ }^{[26]}$. Notably, nearly all the uP450 variants (41/44) were found to exhibit measurable oxidation activity on both 1 and the larger substrate $\mathbf{2}$ (Table S2). These include the variants whose concentration was below the detection limit for the $\mathrm{CO}$ binding assay (e.g. pAmF variants and Thr327UAA variants, Figure 2). Not surprisingly, the substrate conversion ratio varied considerably as a result of the different reactivity of the enzymes as well as their difference in concentration in the lysate.

As shown by these data (Table S2), incorporation of the four non-proteinogenic amino acids at the various active site positions altered the product distribution for the oxidation of $\mathbf{1}$ and/or 2 to a varying degree. Interestingly, a new oxidation product was produced in the presence of the latter, which was determined to correspond to $9(R)$-hydroxy-nootkatone ( 7 , Scheme 1). Inspection of these results allowed for a first general evaluation of the relative effect of each type of UAA on the enzyme site-selectivity. As summarized in Figure 3, about one-third (31\%) out of the 88 possible uP450/substrate combinations displayed at least a moderate change in regioselectivity, with this effect being fairly evenly distributed across all unnatural amino acids except $\mathrm{pAmF}$. Using the more stringent threshold of $>30 \%$ variation in site selectivity, this number is reduced to 15 uP450s. Among these, the ObnY- and pAcFcontaining variants are more largely represented as compared to the NapA- and pAmFcontaining uP450s (Figure 3), indicating that substitutions with the former two UAAs have 
in general a larger effect on the enzyme site selectivity. Finally, analysis of the variants with the largest variation in product distribution $(>50 \%)$ revealed that mutagenesis with $\mathrm{pAcF}$ has the largest potential in causing dramatic changes in the regioselectivity of oxidation.

The dependence of these changes on the substrate, site targeted for mutagenesis, and nature of the parental residue was also examined. On average, a larger number of important shifts in regioselectivity ( $>30 \%$ variation vs. parent enzyme) were observed in the context of $(S)$ ibuprofen ME (1) as compared to (+)-nootkatone (2) (10 vs. 6, Table S2), which may reflect the fact that altering the orientation of a smaller substrate within the enzyme active site is easier than for a bulkier molecule.

Furthermore, the largest regioselectivity shifts were observed for substitutions involving amino acid residues whose $\beta$-carbon is within $12-13 \AA$ from the heme iron (i.e. positions 78 , 82,328 , Figure 1), which supports our previously advanced hypothesis that first-sphere active-site residues are most preferable targets for modulating this property in $\mathrm{P} 450 \mathrm{~s} .{ }^{[3 \mathrm{~m}]}$ Finally, with respect to the dependence of the regioselectivity changes on the nature of the parental residue, the following order emerged from the data of Table S2: Ala (largest changes) $>\mathrm{Val} /$ Leu $\gg$ Phe (smallest changes). This trend can be rationalized on the basis of the structural difference between the side chain group of the UAAs and that of the substituted amino acid in the parental sequence.

Other interesting observations could be made from side-by-side comparison of variants incorporating different unnatural amino acids at the same position of the active site (Table 1). For example, substitution of position 78 and 82 (Figure 1) with any of the four UAAs resulted in significantly different product profiles for the oxidation of $\mathbf{2}$, whereas little or no change in regioselectivity was observed for these variants in the oxidation of 1 (Entries 2-9, Table 1). Conversely, introduction of either $\mathrm{OBnY}$ or $\mathrm{pAcF}$ at position 181 was found to induce a large shift in the regioselectivity of oxidation with $\mathbf{1}$, while both variants exhibited a parent-like product profile in the presence of $\mathbf{2}$. Thus, beyond the general trends discussed above, these results illustrate the capability of the different UAA considered here to induce unique changes in regioselectivity, as dependent on the structure of substrate as well as the site targeted for mutagenesis.

\section{Characterization of the most selective uP450 variants}

The experiments above revealed that a number of uP450s exhibited a significant improvement in regioselectivity as compared to the parent enzyme. Accordingly, the most selective variants, namely Ala78pAcF, Ala82pAcF, and Ala328NapA, were isolated and further characterized in purified form (Table 2).

As shown in Scheme 1, the parent enzyme is unselective in the oxidation of $(S)$-ibuprofen ME (1), producing a 38:62 mixture of the $\mathrm{C}^{\prime}{ }^{\prime}$ and $\mathrm{C}^{\prime}$ hydroxylation products. From the small library of uP450s, two variants could be isolated that exhibit much higher regioselectivity toward each of these aliphatic sites. Specifically, variant Ala78pAcF was found to hydroxylate the $\mathrm{C}^{\prime}$ ' benzylic position with $88 \%$ regioselectivity, whereas variant Ala328NapA produces the hydroxylated product 3 with 95\% regioselectivity (Table 2). Similarly, two variants could be identified that exhibit a large shift in selectivity toward C- 
H hydroxylation over epoxidation in (+)-nootkatone (2). Indeed, variant Ala82pAcF shows greatly improved regioselectivity for hydroxylation of the C13 site as compared to 139-3, resulting in the formation of 6 with $62 \%$ selectivity as compared to a mere $4 \%$ for the parent enzyme. On the other hand, variant Ala78pAcF catalyzes the formation of $9(R)$-hydroxynootkatone (7), not produced by the parent enzyme, with high regioselectivity (73\%) and absolute stereoselectivity, as judged by the lack of formation of the corresponding epimer (9(S)-hydroxy-nootkatone). Consistent with the general trend emerging from our previous analysis (Figure 3), three out of the four most selective transformations are mediated by pAcF-containing uP450s. These results thus confirm the highest potential of this UAA, among those tested, toward affecting the site selectivity in a P450.

139-3 catalyzes the oxidation of the target substrates with good efficiency, supporting nearly 8,000 total turnovers (TTN) with $\mathbf{1}$ and about 7,000 TTN with $\mathbf{2}$ (Table 2) with initial product formation rates of 420 and $175 \mathrm{~min}^{-1}$, respectively. Comparison of the TTN values and product formation rates for the uP450 variants show that both these properties are affected by the UAA substitutions (Table 2). In each case (i.e. for Ala78pAcF, Ala82pAcF and Ala328NapA), the improvement in regioselectivity in the presence of $\mathbf{1}$ and/or $\mathbf{2}$ is accompanied by a 3- to 10-fold reduction in TTN. Measurement of the coupling efficiency for these variants showed that the decrease in TTN is, in most cases, corresponded by a reduction in coupling efficiency, which could lead to a faster inactivation of the enzyme during catalysis. For the Ala328NapA and Ala82pAcF variants, the improvement in regioselectivity in the transformation of $\mathbf{1}$ and $\mathbf{2}$, respectively, is also associated by a decrease in the oxidation rate (Table 2). Interestingly, the data corresponding to these uP450s also indicate that the effect on TTN and catalytic rate is more prominent with the substrate oxidized with higher selectivity, indicating a general trade-off between these properties as we observed with $\mathrm{P} 450$ catalysts evolved using conventional mutagenesis. $[3 \mathrm{~m}, 7]$

These trends notwithstanding, the catalytic efficiency of these selective P450 variants remains elevated (i.e. 700-2,500 total turnovers) and thus well suited for synthetic applications, as established by the successful isolation of $\mathbf{6}$ and $\mathbf{7}$ from large-scale reactions (40 mg (+)-nootkatone) with Ala82pAcF (0.13 mol\%) and Ala78pAcF (0.05 mol\%), respectively (See Experimental Part for details). Most importantly, these results showed that through the screening of a minimal library of UAA-containing P450s (44), selective catalysts could be rapidly obtained for the oxyfunctionalization at a total of four aliphatic $\mathrm{C}$ $-\mathrm{H}$ sites in a small-molecule drug and a complex natural product, including one position not accessible to the parent enzyme.

\section{Activity-enhancing effect of pAmF mutations}

During the initial screening of the uP450 variants from cell lysate, we noticed that the substrate conversion yields obtained with the $\mathrm{pAmF}$-containing P450s were comparable to that observed in the presence of other uP450s. Since the pAmF-containing variants are expressed at much lower levels (Figure 2), these results implied that these enzymes are capable of supporting higher substrate turnover numbers. To investigate this aspect, the most promising variants, namely Leu75pAmF, Phe81pAmF, and Leu188pAmF, were expressed 
and further characterized in purified form. Gratifyingly, these pAmF-containing P450s were indeed found to catalyze the oxidation of $\mathbf{1}$ and $\mathbf{2}$ with much higher efficiency compared not only to the previously characterized uP450s but also to the parent enzyme, supporting two to five times higher TTN than the latter (Table 2). A general increase in the product formation rate, ranging from 2- to 4-fold, was also observed. Notably, the total turnover numbers measured for Leu75pAmF with (+)-nootkatone (2) $(34,650)$ corresponds to the highest TTN value reported for an engineered $\mathrm{P} 450$ on a complex molecule. ${ }^{[5]}$ Moreover, the catalytic rate for Leu188pAmF on $\mathbf{1}\left(1,220 \mathrm{~min}^{-1}\right)$ approaches that exhibited by wild-type CYP102A1 on fatty acid substrates (e.g. 1,680 $\mathrm{min}^{-1}$ with laurate ${ }^{[27]}$ ), which themselves remain among the highest ones among known natural P450s.

The beneficial effect of pAmF substitutions on the catalytic efficiency of the monoxygenase was unanticipated, calling for further investigations to examine the basis of this phenomenon. Analysis of the product distribution for the pAmF-containing variants with both $\mathbf{1}$ and $\mathbf{2}$ showed no significant changes as compared to that of parent enzyme in nearly all cases (5/6, Table 1), suggesting that these activity enhancements are not linked to a change in the binding mode of the substrate upon oxidation. Furthermore, inspection of the enzyme crystal structure (Figure 1) revealed that, unlike the regioselectivity-altering mutations, these activity-enhancing substitutions are not restricted to amino acid residues located in close proximity to the heme cofactor. Indeed, these sites included Leu188, whose $\beta$ carbon lies rather far (i.e. $20 \AA$ ) from the heme iron center (Figure 1).

Given the H-bonding capabilities of the aromatic amino group in pAmF and the presence of various H-bond donor/acceptor groups in both $\mathbf{1}$ and $\mathbf{2}$, we wondered whether the improved catalytic efficiency of the pAmF-containing variants could stem from an increase in the enzyme affinity for the substrate. To investigate this aspect, heme spin shift experiments were carried out. While $(S)$-ibuprofen ME (1) failed to induce a detectable spectral shift of the Soret band in the presence of both 139-3 and the pAmF variants, a significant shift of the heme spin state (from $20 \%$ to $60 \%$ ) could be observed upon addition of (+)-nootkatone (2) to these P450s (Figure 4). Calculation of the equilibrium dissociation constants indicated that the affinity of the pAmF variants for $\mathbf{2}$ are relatively high, with the corresponding $\mathrm{K}_{\mathrm{D}}$ values ranging from 16 to $32 \mu \mathrm{M}$ (Figure 4). However, these values were found to be comparable to that of the parent enzyme $\left(\mathrm{K}_{\mathrm{D}}=14 \mu \mathrm{M}\right)$, suggesting that the $\mathrm{pAmF}$ substitutions do not significantly improve the enzyme binding affinity for this substrate. Moreover, these experiments show no apparent correlation between the extent of $\mathbf{2}$-induced heme spin shift and the difference in catalytic performance for these P450s (Figure 4).

In contrast, measurement of the coupling efficiency revealed a good correlation between this parameter and the improved catalytic properties of these variants across both substrates (Table 2). With (+)-nootkatone (2), both the product formation rate and TTN values were found to increase almost linearly with the increase in coupling efficiency (Table 2).

Although a less direct correlation is observable with $(S)$-ibuprofen ME (1), also in this case the fastest and most efficient variant, Leu188pAmF, is characterized by the highest coupling efficiency (Table 2). 


\section{Tyrosine vs. pAmF substitutions}

Among the natural amino acids, tyrosine is most closely related to $\mathrm{pAmF}$ from a structural standpoint, which raised the question of whether the beneficial effects obtained with this non-proteinogenic amino acid could be reproduced by tyrosine. To address this point, the 139-3-based single mutant Leu75Tyr, Phe81Tyr, and Leu188Tyr were prepared and characterized (Table 2). Interestingly, similarly to the pAmF variants, tyrosine substitutions at each of these sites was found to induce a significant increase in catalytic rate with both 1 (2- to 3-fold) and 2 (4- to 9-fold) vs. the parent P450. These variants also showed, for the most part, parent-like regioselectivity with both $(S)$-ibuprofen ME (1) and (+)-nootkatone (2) as well as parent-like binding affinity for $2\left(\mathrm{~K}_{\mathrm{D}}: 14-48 \mu \mathrm{M}\right.$, Figure $\left.\mathrm{S} 2\right)$, as observed for the pAmF-incorporating counterparts. In spite of these similar features, the pAmF variants remained significantly superior oxidation catalysts in terms of total turnover numbers as compared to the Tyr-substituted counterparts. This general trend is apparent with (+)nootkatone (2), e.g. with Leu75pAmF supporting nearly 3-fold higher total turnovers than Leu75Tyr (34,650 vs. 11,640 TTN), but it is particularly striking in the case of $(S)$-ibuprofen ME (1) (Table 2). With the latter, the turnover numbers supported by the pAmF variants are indeed up to 7-fold higher than those obtained with the corresponding Tyr-containing P450s.

Altogether, the studies above showed the distinctive advantage of pAmF substitutions toward enhancing the catalytic efficiency of the P450. This beneficial effect apparently stems from their ability to promote a more efficient oxidation of the substrate by the enzyme, as suggested by the correlation between TTN and coupling efficiency discussed earlier. This phenomenon has been linked to a more favorable enzyme-substrate interaction. ${ }^{[8,28]}$ However, our binding studies (i.e. $K_{D}$ values, heme spin shift assays) with both the pAmF variants and their Tyr-substituted counterparts do not support this scenario. As an alternative hypothesis, the $\mathrm{pAmF}$ substitutions could be beneficial toward suppressing unproductive, ROS-producing pathways during the P450 catalytic cycle, resulting in a slower inactivation of the enzyme and thus higher total turnover numbers. How this effect is exerted by pAmF substitutions at multiple sites within the enzyme active site (i.e. 75, 81, 188 ) and across structurally different substrates remains yet unclear at the moment.

\section{Comparison with natural amino acid mutagenesis}

Based on the data accumulated at this point, it became apparent that $\mathrm{pAcF}$ and $\mathrm{pAmF}$ have a distinctive ability to induce dramatic changes in the regioselectivity and catalytic efficiency, respectively, of a P450 enzyme. To further examine whether these effects could have been achieved with any of the natural amino acids, two of the targeted active site positions, namely Ala75 and Leu78, were also subjected to site-saturation mutagenesis. Position 78 was chosen because its substitution with $\mathrm{pAcF}$ causes one of the largest regioselectivity shifts observed in this study ( $0 \% \rightarrow 73 \%$ for $\mathrm{C} 9$ site in 2 ), leading to a variant capable of hydroxylating a $\mathrm{C}-\mathrm{H}$ bond, not accessible to the parent enzyme, with high regio- and stereoselectivity. On the other hand, position 75 was chosen based on the fact that its substitution with pAmF results in the most efficient P450 catalyst identified here (>34,600 TTN with 2). In addition, Leu $75 \mathrm{pAmF}$ also exhibits greatly improved regioselectivity toward hydroxylation of $\mathrm{C} 2^{\prime}$ in $(S)$-ibuprofen ME (1) compared to 139-3 (38 $\rightarrow 86 \%$, Table $1)$. 
Accordingly, two site-saturation libraries (75NNK and 78NNK) were constructed by mutating positions 75 and 78 in 139-3 using the degenerate codon NNK (any base in first and second position; $\mathrm{G}$ or $\mathrm{T}$ in third position). The functional members from each library (3fold oversampling) were then identified via high-throughput fingerprinting ${ }^{[29]}$, followed by analysis of their oxidation activity on $\mathbf{1}$ and $\mathbf{2}$ via in vitro reactions. Analysis of the reactions with (+)-nootkatone (2) showed that all the variants from these libraries exhibit parent-like regioselectivity. In addition, the most active variant within this pool of engineered P450s was estimated to support at most 2-fold higher TTN than the parent enzyme. Thus, none of the 75 or 78 site-saturation variants could reproduce the catalytic and site selectivity features of Leu75pAmF and Leu78pAcF, respectively. Similarly, none of the P450 variants from the $75 \mathrm{NNK}$ library could reproduce the large regioselectivity shift displayed by Leu75pAmF with $(S)$-ibuprofen ME (1) as the substrate. Indeed, the highest C2'-selectivity observed among these variants was $71 \%$ ( $v s .86 \%$ for Leu $75 \mathrm{pAmF}$ ), with the minor product (29\%) being 3 . Altogether, these experiments along with the studies on the Tyr mutants, showed that none of the amino acid mutations accessible via conventional mutagenesis could reproduce the largest functional changes imparted by the $\mathrm{pAcF}$ and $\mathrm{pAmF}$ substitutions.

\section{Conclusion}

In conclusion, we have investigated the site-selective incorporation of various unnatural amino acids into a cytochrome P450 and the effect of these modifications on its selectivity and reactivity properties. Our results show that different aromatic unnatural amino acids, including two comprising large (naphtyl) and extended (benzyloxybenzene) side-chain groups, can be accommodated at multiple positions (10/11) within the active site of the enzyme. Importantly, via screening of this minimal library of singly substituted uP450s, selective $\mathrm{P} 450$ catalysts for the hydroxylation of a total of four aliphatic $\mathrm{C}-\mathrm{H}$ sites in a drug molecule and a complex natural product could be rapidly identified. A particularly interesting trend emerging from these studies involves the inherent potential of $\mathrm{pAcF}$ substitutions, in particular at the level of 'first-sphere' active site positions, toward altering the site selectivity of a P450 monooxygenase. Another most relevant finding concerns the general activity-enhancing effect of active site substitutions with $\mathrm{pAmF}$, which resulted in P450 catalysts capable of supporting among the highest numbers of total turnovers reported so far for an engineered P450. These findings are expected to have immediate implications in the design and develoment of improved P450-based oxidation catalysts. They also lay the ground for future studies aimed, for example, at elucidating the mechanism underlying the activity-enhancing effects of $\mathrm{pAmF}$ substitutions and further examining the generality of these effects (e.g. in the context of other P450 systems). In the future, it will be also interesting to determine whether the effects of $\mathrm{pAmF}$ and $\mathrm{pAcF}$ substitutions can be combined. Importantly, our studies showed that the functional changes induced by these non-proteinogenic amino acids could not be recapitulated by any of the natural amino acids. As such, this work provides a first demonstration that unnatural mutagenesis constitutes a promising strategy to modulate and enhance the selectivity and catalytic efficiency of P450based oxidation catalysts. 


\section{Experimental Section}

\section{Reagents and analytical methods}

Chemical reagents and solvents were purchased from Sigma-Aldrich, AlfaAesar, ChemImpex, and Fluka. Silica gel chromatography purifications were carried out using AMD Silica Gel 60 230-400 mesh. 1D and 2D NMR experiments were carried out on a Brüker $500 \mathrm{MHz}$ spectrometer. Data for ${ }^{1} \mathrm{H}$ NMR spectra are reported in the conventional form: chemical shift $(\delta \mathrm{ppm})$, multiplicity ( $\mathrm{s}=$ singlet, $\mathrm{d}=$ doublet, $\mathrm{t}=$ triplet, $\mathrm{q}=$ quartet, $\mathrm{m}=$ multiplet, br=broad), coupling constant $(\mathrm{Hz})$, integration. Data for ${ }^{13} \mathrm{C}$ NMR spectra are reported in terms of chemical shift $(\delta \mathrm{ppm})$. Mass spectra were collected by direct infusion on a Thermo Scientific LTQ Velos ESI/ion-trap mass spectrometer. Gas chromatography analyses were carried out on a Shimadzu GC2010 equipped with a FID detector and a Restek RTX-5 column $(15 \mathrm{~m} \times 0.25 \mathrm{~mm} \times 0.25 \mu \mathrm{m}$ film). Separation methods: $(S)$-ibuprofen methyl ester (1): $260^{\circ} \mathrm{C}$ inlet, $260^{\circ} \mathrm{C}$ detector, $120^{\circ} \mathrm{C}$ oven, $17^{\circ} \mathrm{C} / \mathrm{min}$ ramp to $150^{\circ} \mathrm{C}, 10^{\circ} \mathrm{C} / \mathrm{min}$ ramp to $240^{\circ} \mathrm{C}$, and $240^{\circ} \mathrm{C}$ for $1 \mathrm{~min}$; (+)-Nootkatone (2): $260^{\circ} \mathrm{C}$ inlet, $260^{\circ} \mathrm{C}$ detector, $120^{\circ} \mathrm{C}$ oven, $12^{\circ} \mathrm{C} / \mathrm{min}$ ramp to $220^{\circ} \mathrm{C}, 220^{\circ} \mathrm{C}$ for $1 \mathrm{~min}, 20^{\circ} \mathrm{C} / \mathrm{min}$ ramp to $250^{\circ} \mathrm{C}$, and $250^{\circ} \mathrm{C}$ for $1 \mathrm{~min}$.

\section{Synthesis of (S)-ibuprofen methyl ester (1)}

$(S)$-Ibuprofen (341 mg, $1.65 \mathrm{mmol})$ and sulphuric acid $(100 \mu \mathrm{L})$ was refluxed for $16 \mathrm{hrs}$ in methanol $(20 \mathrm{~mL})$. Saturated sodium bicarbonate $(10 \mathrm{~mL})$ was added, followed by evaporation of methanol under reduced pressure. The solution was then extracted with dichloromethane $(3 \times 5 \mathrm{~mL})$. The organic layers were dried over sodium sulphate and evaporated to give a colourless oil, which was purified by flash chromatography (8:1 of hexanes:ethyl acetate mixture) to yield (1) $(245 \mathrm{mg}, 67 \%) .{ }^{1} \mathrm{H} \mathrm{NMR}\left(500 \mathrm{MHz}, \mathrm{CDCl}_{3}\right): \delta=$ 0.90 (d, $6 \mathrm{H}, J=6.7 \mathrm{~Hz}), 1.49$ (d, $3 \mathrm{H}, J=7.2 \mathrm{~Hz}), 1.85$ (septet, $1 \mathrm{H}, J=6.9 \mathrm{~Hz}$ ), 2.45 (d, 2 $\mathrm{H}, J=6.9 \mathrm{~Hz}), 3.66(\mathrm{~s}, 1 \mathrm{H}), 3.70(\mathrm{q}, 1 \mathrm{H}, J=7.2 \mathrm{~Hz}), 7.09(\mathrm{~d}, 2 \mathrm{H}, J=7.7 \mathrm{~Hz}), 7.20(\mathrm{~d}, 2$ $\mathrm{H}, J=8.1 \mathrm{~Hz}):{ }^{13} \mathrm{C} \mathrm{NMR}\left(125 \mathrm{MHz}, \mathrm{CDCl}_{3}\right): \delta=18.65,22.42,30.18,45.04,51.98,127.13$, 129.356, 137.75, 140.56, 175.23; MS (ESI) calcd for $\mathrm{C}_{14} \mathrm{H}_{20} \mathrm{O}_{2}[\mathrm{M}+\mathrm{H}]^{+} \mathrm{m} / z: 221.15$; found: 221.20 .

\section{Synthesis of the unnatural amino acids}

pAcF was synthesized starting from acetophenone as described by Satyanarayana et al.. ${ }^{[30]}$ ObnY was prepared from L-tyrosine according to the synthetic procedures reported by Stokes et al.. ${ }^{[22]}$ NMR and MS data for these compounds were consistent with those reported. pAmF and NapA were purchased from AlphaAesar and Sigma-Aldrich, respectively.

\section{Cloning and plasmid construction}

A pCWori-based vector encoding for the CYP102A1 variant $139-3^{[3 a]}$ was kindly provided by the Arnold group (Caltech). Compared to wild-type CYP102A1, 139-3 contains the following mutations: V78A, H138Y, T175I, V178I, A184V, H236Q, E252G, R255S, A290V, A295T, L353V. Vectors encoding for the amber stop codon-containing P450 variants were prepared using pCWori_139-3 as a template, primers BamHI_2_fwd (5'GGAAACAGGATCCATCGATGC-3') and SacI_2_rev (5'- 
AATATCGAGCTCGTAGTTTGTATGATC-3') as megaprimers, and the oligonucleotides of Table $\mathrm{S} 1$ as mutagenizing primers. The target gene products $(1.5 \mathrm{Kbp})$ were prepared by PCR overlap extension mutagenesis, digested with $\mathrm{BamH}$ I and $\mathrm{Sac}$ I restriction enzymes, and ligated to $\mathrm{BamH} \mathrm{I} / \mathrm{Sac}$ I double-digested pCWori vector. The plasmid pEVOL_pAcF encoding for the engineered Methanococcus jannaschii RNA $_{\mathrm{CUA}}$ and aminoacyl-tRNA synthetase for amber codon suppression with pAcF was kindly provided by the Schultz group (TSRI). Plasmids for the expression of the pAmF-RS ${ }^{[20]}$, NapA-RS ${ }^{[23]}$, and ObnY-RS $\left(=\mathrm{Bpa}-\mathrm{RS}(\mathrm{V} 164 \mathrm{~A})^{[22]}\right)$ were prepared by introducing the following mutations in both copies of the AARS gene in the pEVOL_pAcF vector: pAmF-RS: Y32T, E107T, D158P, I159L, L162A; NapA-RS: Y32L, D158P, I159A, L162Q, A167V; ObnY-RS: Y32G, E107P, D158T, I159S, V164A. The plasmid vector for the expression of Yellow Fluorescent Protein containing an amber stop codon after the initial Met residue was prepared by PCR amplification of the YPF gene from pEYFP-N1 (BDbiosciences) using primers YFP(stop)_for (5'-GGTTCCATATGGGTTAGG TGAGCAAGGGCGAGGAGC-3') and YFP_(XhoI)_rev (5'-CGTTGCTCGAGCTTGTACAGCTCGTCCATGCC-3'). The PCR product $(0.7 \mathrm{Kbp})$ was then cloned into pET22b(+) (Novagen) using Nde I and Xho I, giving pET22_YFP(stop) plasmid. The identity of the cloned constructs was confirmed by DNA sequencing.

\section{Protein expression and purification}

The UAA-containing P450s were expressed in E. coli DH5a cells co-transformed with the pCWori-based vector encoding for the $\mathrm{P} 450$ and the appropriate $\mathrm{pEVOL}$ vector encoding for the orthogonal tRNA $\mathrm{CUA}_{\mathrm{A}} / \mathrm{AARS}$ pair. Overnight cultures in LB medium $(100 \mathrm{mg} / \mathrm{L}$ ampicillin, $26 \mathrm{mg} / \mathrm{L}$ chloramphenicol) were used to inoculate M9 media (100 mg/L ampicillin, $26 \mathrm{mg} / \mathrm{L}$ chloramphenicol) supplemented with the appropriate UAA ( $2 \mathrm{mM})$. At an $\mathrm{OD}_{600}$ of 0.6 , protein expression was induced with $0.05 \%$ arabinose, $0.5 \mathrm{mM}$ isopropyl$\beta$-D-thiogalactopyranoside (IPTG), and $0.3 \mathrm{mM} \delta$-aminolevulinic acid, followed by incubation for 24 hours at $27^{\circ} \mathrm{C}$. For the initial screening of the uP450s, the proteins were expressed in $15 \mathrm{~mL}$ cultures, followed by lysis $(0.8 \mathrm{mg} / \mathrm{mL}$ lysozyme, $4 \mathrm{U} / \mathrm{mL}$ deoxyribonuclease I, $10 \mathrm{mM} \mathrm{MgCl} 2,50 \mathrm{mM}$ phosphate buffer, $\mathrm{pH}$ 8.0) and clarification of the cell lysate by centrifugation. For the characterization studies, selected uP450s were expressed from $0.5 \mathrm{~L}$ cultures and purified by ion-exchange chromatography as described ${ }^{[29]}$. P450 concentration was determined from $\mathrm{CO}$ binding difference spectra $\left(\varepsilon_{450-500}=91,000 \mathrm{M}^{-1} \mathrm{~cm}^{-1}\right)$. Phosphite dehydrogenase $(\mathrm{PTDH})$ was expressed and purified as described previously. ${ }^{[29]}$

\section{YFP screen}

E. coli BL21(DE3) cells were co-transformed with the pET22_YFP(stop) plasmid and the pEVOL plasmid encoding for the appropriate aminoacyl-tRNA synthetase, and then grown in Luria-Bertani (LB) media containing ampicillin $(50 \mathrm{mg} / \mathrm{L})$ and chloramphenicol $(26$ $\mathrm{mg} / \mathrm{L}$ ) at $37^{\circ} \mathrm{C}$ overnight. The overnight cultures were used to inoculate 96 -deep well plates containing M9 media. At an $\mathrm{OD}_{600}$ of 0.6 , cell cultures were induced by adding arabinose $(0.06 \% \mathrm{~m} / \mathrm{v})$, IPTG $(0.2 \mathrm{mM})$, and the appropriate unnatural amino acid (final concentration of $1 \mathrm{mM}$ for L-isomer). After overnight growth at $27^{\circ} \mathrm{C}$, the cell cultures were diluted (1:1) with phosphate buffer $(50 \mathrm{mM}, 150 \mathrm{mM} \mathrm{NaCl}, \mathrm{pH} 7.5)$ and fluorescence intensity $\left(\lambda_{\mathrm{ex}}=\right.$ 
$514 \mathrm{~nm} ; \lambda_{\mathrm{em}}=527 \mathrm{~nm}$ ) was determined using a Tecan Infinite 1000 plate reader. Cell cultures containing no unnatural amino acid were included as controls. Each sample was measured in quadruplicate.

\section{Synthesis of 13-hydroxy-nootkatone (6)}

Purified P450 variant Ala82pAcF (1.25 $\mu \mathrm{M} ; 0.13 \mathrm{~mol} \%)$ was dissolved in $183 \mathrm{~mL}$ phosphate buffer $(50 \mathrm{mM}, \mathrm{pH} 8.0)$ in the presence of (+)-nootkatone (40 mg, final conc.: 1.0 $\mathrm{mM})$, PTDH $(2 \mu \mathrm{M}), \mathrm{NADP}^{+}(150 \mu \mathrm{M})$, and sodium phosphite $(50 \mathrm{mM})$. The reaction mixture was stirred for 12 hours at room temperature. The crude product was extracted with dichloromethane $(3 \times 30 \mathrm{~mL})$. The collected organic layers were dried with sodium sulfate, concentrated under vacuum, and purified by flash chromatography ( $0-50 \%$ ethylacetate in hexanes) to afford $\mathbf{6}(22 \mathrm{mg}, 51 \%)$ and $\mathbf{5}(12 \mathrm{mg}, 29 \%)$.

13-hydroxy-nootkatone (6)— ${ }^{1} \mathrm{H}$ NMR $\left(500 \mathrm{MHz}, \mathrm{CDCl}_{3}\right): \delta=0.95(\mathrm{~d}, 3 \mathrm{H}, J=7.0$ $\mathrm{Hz}), 1.11(\mathrm{~s}, 1 \mathrm{H}), 1.15$ (t, $1 \mathrm{H}, J=13.0 \mathrm{~Hz}), 1.37$, (dq, $1 \mathrm{H}, J=3.6,13.4 \mathrm{~Hz}), 1.93-2.06(\mathrm{~m}$, $3 \mathrm{H}), 2.19-2.33$ (m, $2 \mathrm{H}), 2.34-2.47$ (m, $2 \mathrm{H}), 2.52$ (ddt, $1 \mathrm{H}, J=1.9,5.2,14.7 \mathrm{~Hz}), 4.14(\mathrm{~s}$, $2 \mathrm{H}), 4.90(\mathrm{~s}, 1 \mathrm{H}), 5.08(\mathrm{~s}, 1 \mathrm{H}), 5.76(\mathrm{~s}, 1 \mathrm{H}) ;{ }^{13} \mathrm{C} \mathrm{NMR}\left(125 \mathrm{MHz}, \mathrm{CDCl}_{3}\right): \delta=14.91$, 16.81, 32.09, 33.08, 35.98, 39.43, 40.40, 42.04, 44.39, 65.23, 109.08, 124.77, 152.57, 170.27, 199.67; MS (ESI) calcd for $\mathrm{C}_{15} \mathrm{H}_{22} \mathrm{O}_{2}[\mathrm{M}+\mathrm{H}]^{+} m / z: 235.16$; found: 235.2

Nootkatone-11(R), 12-epoxide (5)— ${ }^{1} \mathrm{H}$ NMR (500 MHz, $\left.\mathrm{CDCl}_{3}\right): \delta=0.98(\mathrm{~d}, 3 \mathrm{H}, J=$ $6.8 \mathrm{~Hz}), 1.07$ (s, $3 \mathrm{H}), 1.22(\mathrm{t}, 1 \mathrm{H}, J=12.8 \mathrm{~Hz}), 1.24(\mathrm{~s}, 3 \mathrm{H}), 1.55-1.67(\mathrm{~m}, 1 \mathrm{H}), 1.85-$ 1.93 (m, $1 \mathrm{H}), 1.95-2.09$ (m, $2 \mathrm{H}), 2.19-2.32$ (m, $2 \mathrm{H}), 2.33-2.40$ (m, $1 \mathrm{H}), 2.45$ (dt, $1 \mathrm{H}, J$ $=4.9,13.9 \mathrm{~Hz}), 2.59(\mathrm{~d}, 1 \mathrm{H}, J=4.9 \mathrm{~Hz}), 2.65(\mathrm{~d}, 1 \mathrm{H}, J=4.9 \mathrm{~Hz}), 5.76(\mathrm{~s}, 1 \mathrm{H}) ;{ }^{13} \mathrm{C}$ NMR $\left(125 \mathrm{MHz}, \mathrm{CDCl}_{3}\right): \delta=14.93,16.77,17.77,28.81,32.46,39.01,39.63,40.35,40.54,42.05$, 53.67, 58.94, 124.90, 169.88, 199.51; MS (ESI) calcd for $\mathrm{C}_{15} \mathrm{H}_{22} \mathrm{O}_{2}[\mathrm{M}+\mathrm{H}]^{+} \mathrm{m} / z: 235.16$; found: 235.5 . The stereochemistry of the $\mathrm{C} 11$ carbon atom was assigned via comparison of NMR data with the reported values for the $11(R)^{[25]}$ and $11(S)^{[31]}$ epimer.

\section{Synthesis of $9(R)$-hydroxy-nootkatone (7)}

Purified P450 variant Ala78pAcF (final conc: $0.5 \mu \mathrm{M} ; 0.05 \mathrm{~mol} \%$ ) was dissolved in $183 \mathrm{~mL}$ $50 \mathrm{mM}$ phosphate buffer ( $\mathrm{pH} 8.0)$ in the presence of (+)-nootkatone (40 mg, final conc.: 1.0 $\mathrm{mM})$, PTDH $(2 \mu \mathrm{M}), \mathrm{NADP}^{+}(150 \mu \mathrm{M})$, and sodium phosphite $(50 \mathrm{mM})$. The reaction mixture was stirred for 12 hours at room temperature. The crude product was extracted with dichloromethane $(3 \times 30 \mathrm{~mL})$. The collected organic layers were dried with sodium sulfate, concentrated under vacuum, and purified by flash chromatography (0-50\% ethylacetate in hexanes) to afford 7 (23 mg, 54\%). ${ }^{1} \mathrm{H}$ NMR $\left(500 \mathrm{MHz}, \mathrm{CDCl}_{3}\right): \delta=0.95(\mathrm{~d}, 3 \mathrm{H}, J=6.9$ $\mathrm{Hz}), 1.09$ (t, $1 \mathrm{H}, J=13.5 \mathrm{~Hz}), 1.31(\mathrm{~s}, 3 \mathrm{H}), 1.53(\mathrm{dq}, 1 \mathrm{H}, J=2.6,13.7 \mathrm{~Hz}), 1.76(\mathrm{~s}, 3 \mathrm{H})$, 1.93-2.11 (m, $4 \mathrm{H}), 2.22-2.39$ (m, $2 \mathrm{H}), 2.78$ (tt, $1 \mathrm{H}, J=2.9,12.6 \mathrm{~Hz}), 4.46(\mathrm{t}, 1 \mathrm{H}, J=2.8$ $\mathrm{Hz}), 4.76(\mathrm{~d}, 2 \mathrm{H}, J=12.9 \mathrm{~Hz}), 5.86(\mathrm{~s}, 1 \mathrm{H}) ;{ }^{13} \mathrm{C} \mathrm{NMR}\left(125 \mathrm{MHz}, \mathrm{CDCl}_{3}\right): \delta=14.54$, 18.12, 20.97, 34.00, 37.92, 38.81, 41.21, 42.34, 43.67, 73.36, 109.39, 127.20, 148.91, 168.30, 200.55; MS (ESI) calcd for $\mathrm{C}_{15} \mathrm{H}_{22} \mathrm{O}_{2}[\mathrm{M}+\mathrm{H}]^{+} \mathrm{m} / z$ : 235.16; found: 235.20. The stereochemistry of the $\mathrm{C}(9)$ carbon was assigned based on comparison of the NMR spectral data $\left({ }^{3} \mathrm{~J}^{9,10}=2.80 \mathrm{~Hz}\right)$ with those of analogous compounds (i.e. $9(R)$-hydroxy-11,12dehydro-nootkatone ${ }^{[29] ;} 3^{9}, 10=2.7,3.0 \mathrm{~Hz}$ ). 


\section{Total turnover numbers and regioselectivity of P450 variants}

Analytical-scale reactions ( $1 \mathrm{~mL}$ ) were carried out using $0.02-1 \mu \mathrm{M} \mathrm{P} 450,1 \mathrm{mM}$ substrate, $2 \mu \mathrm{M}$ PTDH, $100 \mu \mathrm{M} \mathrm{NADP}^{+}$, and $50 \mathrm{mM}$ sodium phosphite in phosphate buffer $(50 \mathrm{mM}$, $\mathrm{pH}$ 8.0). The $\mathrm{P} 450$ variants described in Table 2 were characterized in purified form, while those described in Tables 1 and S1 were characterized directly from cell lysates. After 12 hours at room temperature, the reaction mixtures were added with guaiacol $(500 \mu \mathrm{M})$ as internal standard, extracted with dichloromethane, and analyzed by gas chromatography. TTN values were calculated based on the total amount of oxidation products as quantified based on calibration curves. Mean and standard deviation values reported for P450 variants in Table 2 were calculated from experiments performed at least in triplicate.

\section{Measurement of catalytic rate, coupling efficiency, and substrate binding affinity}

Initial product formation rates were measured from $1 \mathrm{~mL}$ scale reactions containing $0.5 \mathrm{mM}$ substrate, $0.02-0.5 \mu \mathrm{M}$ purified P450, and $2 \mathrm{mM}$ NADPH in phosphate buffer $(50 \mathrm{mM}, \mathrm{pH}$ 8.0) at room temperature. After 30 seconds, the samples were added with $500 \mu \mathrm{M}$ guaiacol and extracted with dichloromethane. Cofactor oxidation rate in the presence of substrate was measured by monitoring NADPH depletion at $340 \mathrm{~nm}\left(\varepsilon_{450-500}=6.22 \mathrm{mM}^{-1} \mathrm{~cm}^{-1}\right)$ using $0.02-0.5 \mu \mathrm{M}$ purified P450, $0.5 \mathrm{mM}$ substrate, and $200 \mu \mathrm{M}$ NADPH. Coupling efficiency was calculated from the ratio between the initial product formation rate and the initial NADPH oxidation rate. Reported mean and standard deviation values were calculated from experiments performed at least in triplicate. Binding experiments were performed using 3 $\mu \mathrm{M}$ purified $\mathrm{P} 450$ in phosphate buffer $(50 \mathrm{mM}, \mathrm{pH} 8.0)$ and varying concentrations of the (+)-nootkatone $(2-500 \mu \mathrm{M})$.

\section{Supplementary Material}

Refer to Web version on PubMed Central for supplementary material.

\section{Acknowledgments}

This work was supported by the U.S. National Institute of Health R01 grant GM098628 awarded to R.F. MS instrumentation was supported by the U.S. National Science Foundation grant CHE-0946653. J.N.K. acknowledges support from the U.S. Department of Education GAANN program (P200A120011-13). J.M.Z. and R.R. are grateful to the NFS REU program for financial support.

\section{References}

1. a) Newhouse T, Baran PS. Angew Chem Int Ed. 2011; 50:3362-3374.b) Neufeldt SR, Sanford MS. Acc Chem Res. 2012; 45:936-946. [PubMed: 22554114] c) Bruckl T, Baxter RD, Ishihara Y, Baran PS. Acc Chem Res. 2012; 45:826-839. [PubMed: 22017496]

2. a) Denisov IG, Makris TM, Sligar SG, Schlichting I. Chem Rev. 2005; 105:2253-2277. [PubMed: 15941214] b) Ortiz de Montellano PR. Chem Rev. 2010; 110:932-948. [PubMed: 19769330] c) Shaik S, Cohen S, Wang Y, Chen H, Kumar D, Thiel W. Chem Rev. 2010; 110:949-1017. [PubMed: 19813749]

3. a) Glieder A, Farinas ET, Arnold FH. Nat Biotechnol. 2002; 20:1135-1139. [PubMed: 12368811] b) Xu F, Bell SG, Lednik J, Insley A, Rao Z, Wong LL. Angew Chem Int Ed. 2005; 44:4029-4032.c) Landwehr M, Hochrein L, Otey CR, Kasrayan A, Backvall JE, Arnold FH. J Am Chem Soc. 2006; 128:6058-6059. [PubMed: 16669674] d) Fasan R, Chen MM, Crook NC, Arnold FH. Angew Chem Int Ed. 2007; 46:8414-8418.e) Li S, Chaulagain MR, Knauff AR, Podust LM, Montgomery J, 
Sherman DH. Proc Natl Acad Sci USA. 2009; 106:18463-18468. [PubMed: 19833867] f) Rentmeister A, Arnold FH, Fasan R. Nat Chem Biol. 2009; 5:26-28. [PubMed: 19011638] g) Robin A, Roberts GA, Kisch J, Sabbadin F, Grogan G, Bruce N, Turner NJ, Flitsch SL. Chem Commun. 2009:2478-2480.h) Lewis JC, Mantovani SM, Fu Y, Snow CD, Komor RS, Wong CH, Arnold FH. Chembiochem. 2010; 11:2502-2505. [PubMed: 21108271] i) Weber E, Seifert A, Antonovici M, Geinitz C, Pleiss J, Urlacher VB. Chem Commun. 2011; 47:944-946.j) Bordeaux M, Galarneau A, Fajula F, Drone J. Angew Chem Int Ed. 2011; 50:2075-2079.k) Kille S, Zilly FE, Acevedo JP, Reetz MT. Nat Chem. 2011; 3:738-743. [PubMed: 21860465] 1) Rea V, Kolkman AJ, Vottero E, Stronks EJ, Ampt KA, Honing M, Vermeulen NP, Wijmenga SS, Commandeur JN. Biochemistry. 2012; 51:750-760. [PubMed: 22208729] m) Zhang KD, Shafer BM, Demars MD, Stern HA, Fasan R. J Am Chem Soc. 2012; 134:18695-18704. [PubMed: 23121379] n) Bordeaux M, Galarneau A, Drone J. Angew Chem Int Ed. 2012; 51:10712-10723.

4. Podust LM, Sherman DH. Nat Prod Rep. 2012; 29:1251-1266. [PubMed: 22820933]

5. Fasan R. ACS Catal. 2012; 2:647-666.

6. van Vugt-Lussenburg ABM, Stjernschantz E, Lastdrager J, Oostenbrink C, Vermeulen NPE, Commandeur JNM. J Med Chem. 2007; 50:455-461. [PubMed: 17266197]

7. Kolev JN, O’Dwyer KM, Jordan CT, Fasan R. ACS Chem Biol. 2014; 9:164-173. [PubMed: 24206617]

8. Fasan R, Meharenna YT, Snow CD, Poulos TL, Arnold FH. J Mol Biol. 2008; 383:1069-1080. [PubMed: 18619466]

9. a) Liu CC, Schultz PG. Ann Rev Biochem. 2010; 79:413-444. [PubMed: 20307192] b) Johnson JA, Lu YY, Van Deventer JA, Tirrell DA. Curr Opin Chem Biol. 2010; 14:774-780. [PubMed: 21071259]

10. a) Seyedsayamdost MR, Xie J, Chan CT, Schultz PG, Stubbe J. J Am Chem Soc. 2007; 129:15060-15071. [PubMed: 17990884] b) Jackson JC, Hammill JT, Mehl RA. J Am Chem Soc. 2007; 129:1160-1166. [PubMed: 17263397]

11. a) Wu N, Deiters A, Cropp TA, King D, Schultz PG. J Am Chem Soc. 2004; 126:14306-14307. [PubMed: 15521721] b) Deiters A, Groff D, Ryu Y, Xie J, Schultz PG. Angew Chem Int Ed. 2006; 45:2728-2731.c) Groff D, Thielges MC, Cellitti S, Schultz PG, Romesberg FE. Angew Chem Int Ed. 2009; 48:3478-3481.

12. a) Lampe JN, Floor SN, Gross JD, Nishida CR, Jiang Y, Trnka MJ, Ortiz de Montellano PR. J Am Chem Soc. 2008; 130:16168-16169. [PubMed: 18998650] b) Lampe JN, Brandman R, Sivaramakrishnan S, de Montellano PR. J Biol Chem. 2010; 285:9594-9603. [PubMed: 20097757]

13. Aldag C, Gromov IA, Garcia-Rubio I, von Koenig K, Schlichting I, Jaun B, Hilvert D. Proc Natl Acad Sci USA. 2009; 106:5481-5486. [PubMed: 19293375]

14. Kimata Y, Shimada H, Hirose T, Ishimura Y. Biochem Biophys Res Commun. 1995; 208:96-102. [PubMed: 7887971]

15. a) Jackson JC, Duffy SP, Hess KR, Mehl RA. J Am Chem Soc. 2006; 128:11124-11127. [PubMed: 16925430] b) Ugwumba IN, Ozawa K, Xu ZQ, Ely F, Foo JL, Herlt AJ, et al. J Am Chem Soc. 2011; 133:326-333. [PubMed: 21162578]

16. Cirino PC, Tang Y, Takahashi K, Tirrell DA, Arnold FH. Biotechnol Bioeng. 2003; 83:729-734. [PubMed: 12889037]

17. Narhi LO, Fulco AJ. J Biol Chem. 1987; 262:6683-6690. [PubMed: 3106360]

18. Whitehouse CJ, Bell SG, Wong LL. Chem Soc Rev. 2012; 41:1218-1260. [PubMed: 22008827]

19. Munro AW, Leys DG, McLean KJ, Marshall KR, Ost TW, Daff S, Miles CS, Chapman SK, Lysek DA, Moser CC, Page CC, Dutton PL. Trends Biochem Sci. 2002; 27:250-257. [PubMed: 12076537]

20. Santoro SW, Wang L, Herberich B, King DS, Schultz PG. Nat Biotechnol. 2002; 20:1044-1048. [PubMed: 12244330]

21. Wang L, Zhang Z, Brock A, Schultz PG. Proc Natl Acad Sci USA. 2003; 100:56-61. [PubMed: 12518054]

22. Stokes AL, Miyake-Stoner SJ, Peeler JC, Nguyen DP, Hammer RP, Mehl RA. Mol Biosyst. 2009; 5:1032-1038. [PubMed: 19668869] 
23. Wang L, Brock A, Schultz PG. J Am Chem Soc. 2002; 124:1836-1837. [PubMed: 11866580]

24. a) McLendon G, Radany E. J Biol Chem. 1978; 253:6335-6337. [PubMed: 687388] b) Parsell DA, Sauer RT. J Biol Chem. 1989; 264:7590-7595. [PubMed: 2651442] c) Inoue I, Rechsteiner M. J Biol Chem. 1994; 269:29241-29246. [PubMed: 7961892]

25. Gliszczynska A, Lysek A, Janeczko T, Switalska M, Wietrzyk J, Wawrzenczyk C. Bioorg Med Chem. 2011; 19:2464-2469. [PubMed: 21377882]

26. McLachlan MJ, Johannes TW, Zhao H. Biotechnol Bioeng. 2008; 99:268-274. [PubMed: 17615560]

27. Huang WC, Westlake AC, Marechal JD, Joyce MG, Moody PC, Roberts GC. J Mol Biol. 2007; 373:633-651. [PubMed: 17868686]

28. Kadkhodayan S, Coulter ED, Maryniak DM, Bryson TA, Dawson JH. J Biol Chem. 1995; 270:28042-28048. [PubMed: 7499289]

29. Zhang K, El Damaty S, Fasan R. J Am Chem Soc. 2011; 133:3242-3245. [PubMed: 21341707]

30. Satyanarayana M, Vitali F, Frost JR, Fasan R. Chem Commun. 2012; 48:1461-1463.

31. Sowden RJ, Yasmin S, Rees NH, Bell SG, Wong LL. Org Biomol Chem. 2005; 3:57-64. [PubMed: 15602599] 


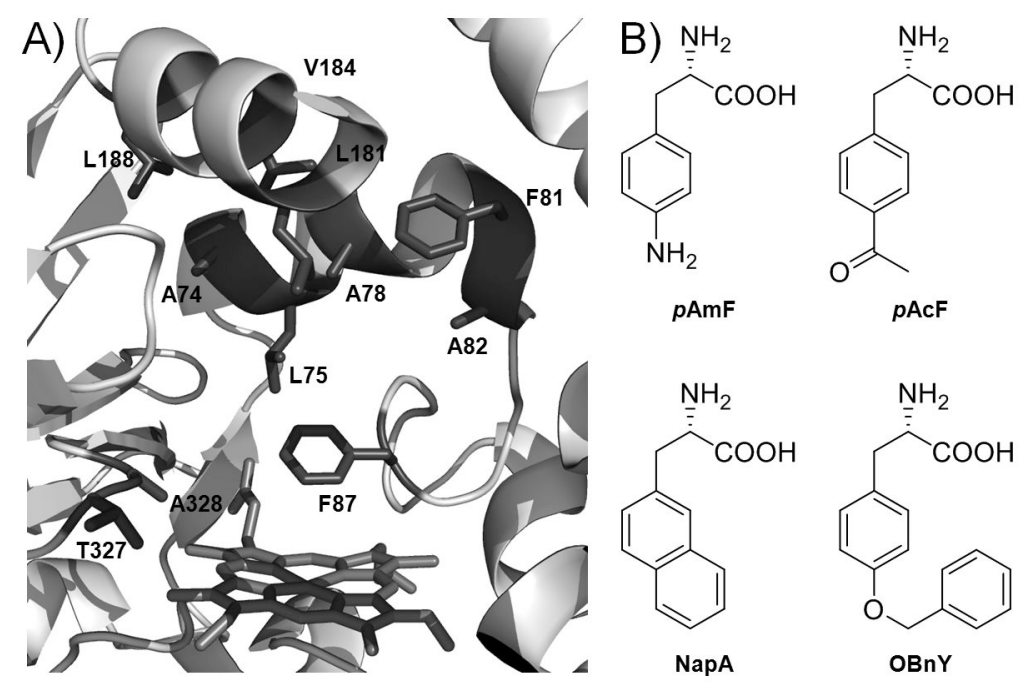

Figure 1.

Target active site positions and unnatural amino acids. A) View of the active site of CYP102A1 variant 139-3 (PDB code 3CBD). The heme group and amino acid residues targeted for mutagenesis are displayed as stick models. B) Chemical structures of the unnatural amino acids investigated in this study ( $p$ AmF: para-amino-phenylalanine; $p$ AcF: para-acetyl-phenyalanine; NapA: 3-(2-naphthyl)-alanine; ObnY: O-benzyl-tyrosine). 


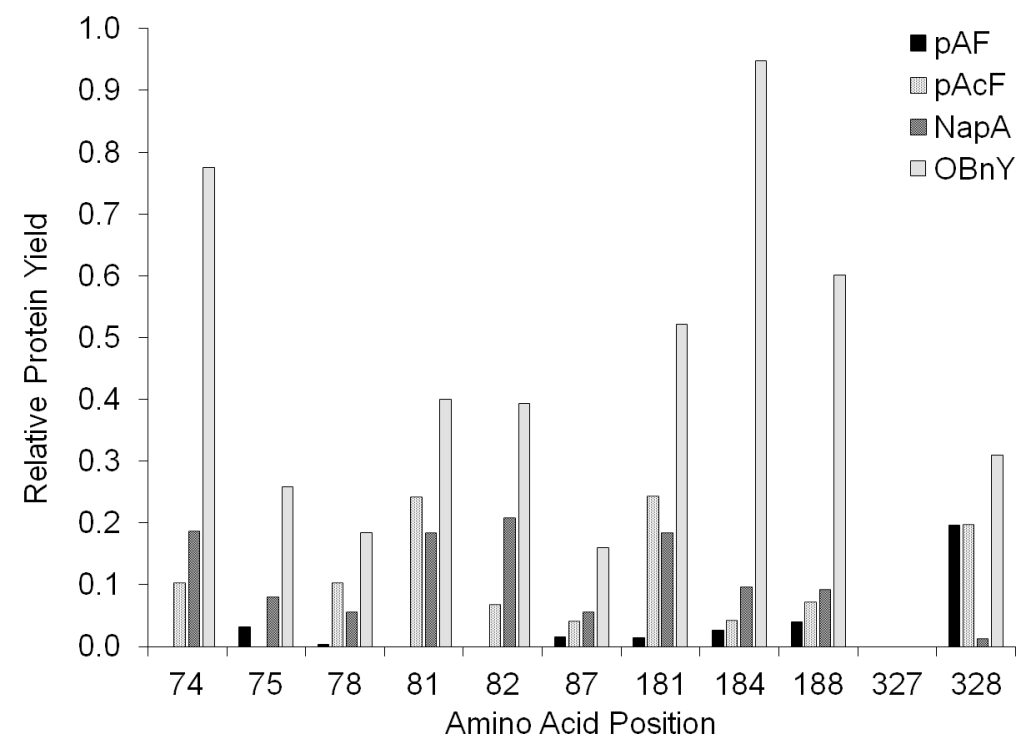

Figure 2.

Relative expression yield for the uP450 variants (normalized to that of the parent enzyme, 139-3). 


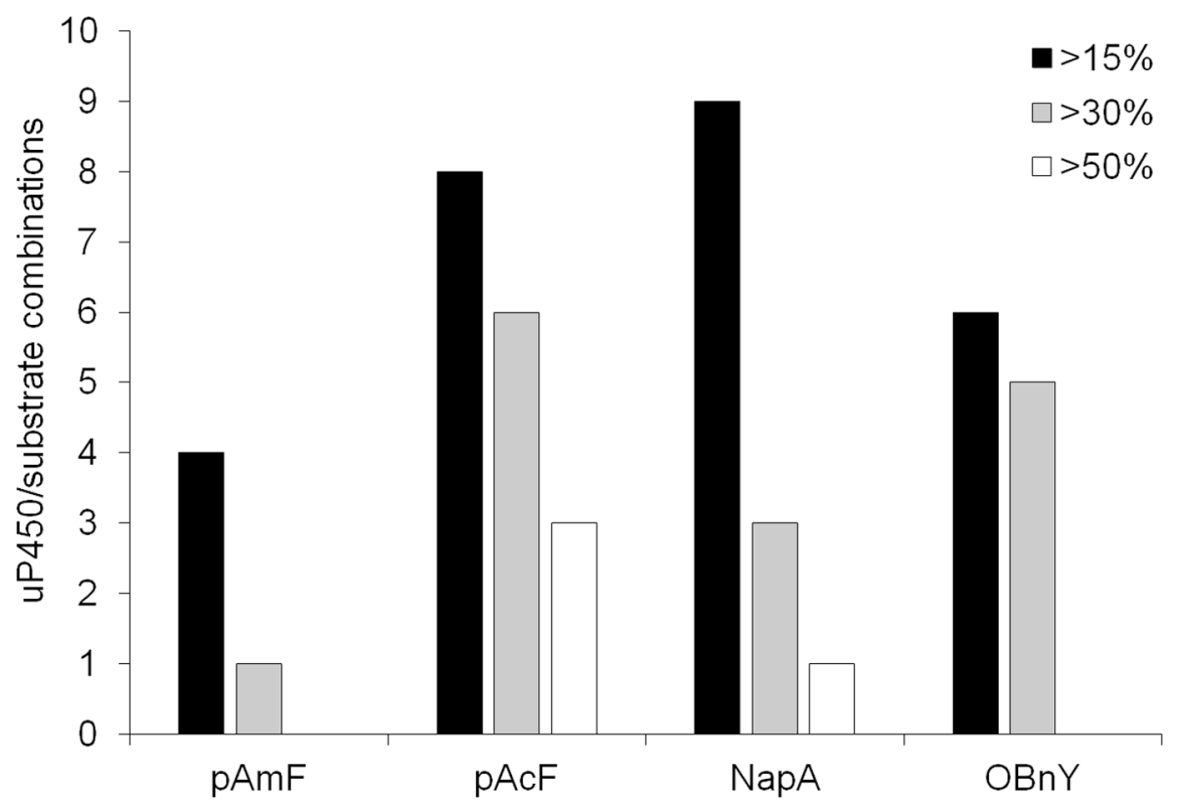

Figure 3.

Distribution of uP450/substrate (1 or $\mathbf{2}$ ) combinations showing more than $15 \%, 30 \%$, or $50 \%$ change in site-selectivity divided according to the type of unnatural amino acid incorporated into the $\mathrm{P} 450$. 
A)

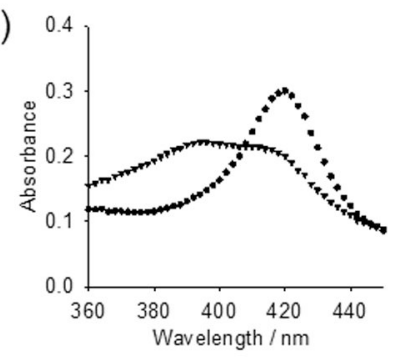

B)

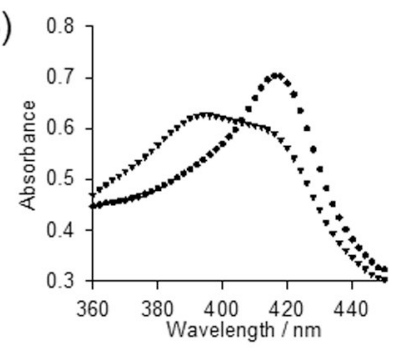

C)

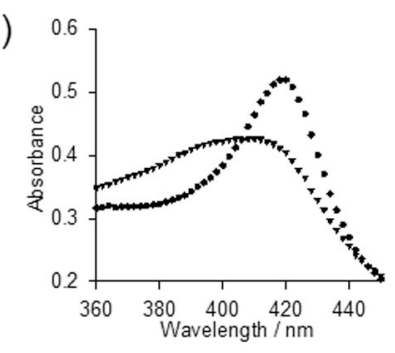

D)

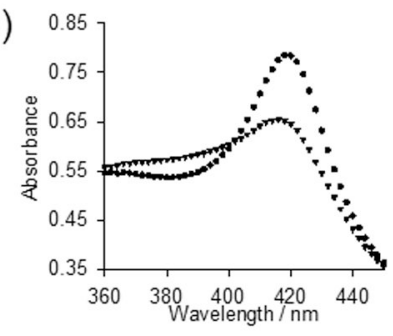

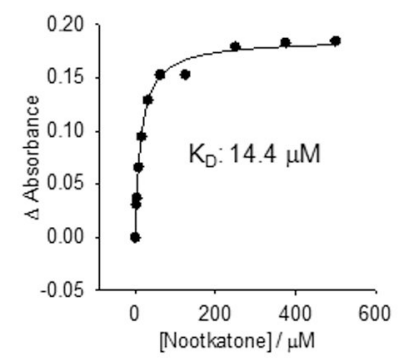
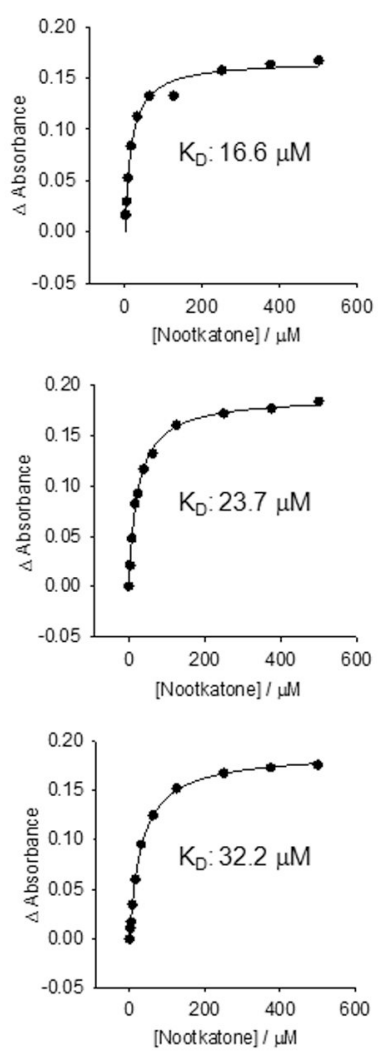

Figure 4.

Heme spin shift experiments with the pAmF-substituted P450s (A; parent P450, B:

Leu75pAmF; B: Phe81pAmF; C: Leu188pAmF). Left panel: Electronic absorption spectrum before (circles) and after (triangles) addition of (+)-nootkatone at saturating concentration $(0.5 \mathrm{mM})$. Right panel: Representative plots of the enzyme heme spin shift at varying (+)nootkatone concentration. The equilibrium dissociation constants $\left(\mathrm{K}_{\mathrm{D}}\right)$ as calculated by fitting the experimental data (dots) to a non-cooperative 1:1 binding model equation (solid line), are indicated. 

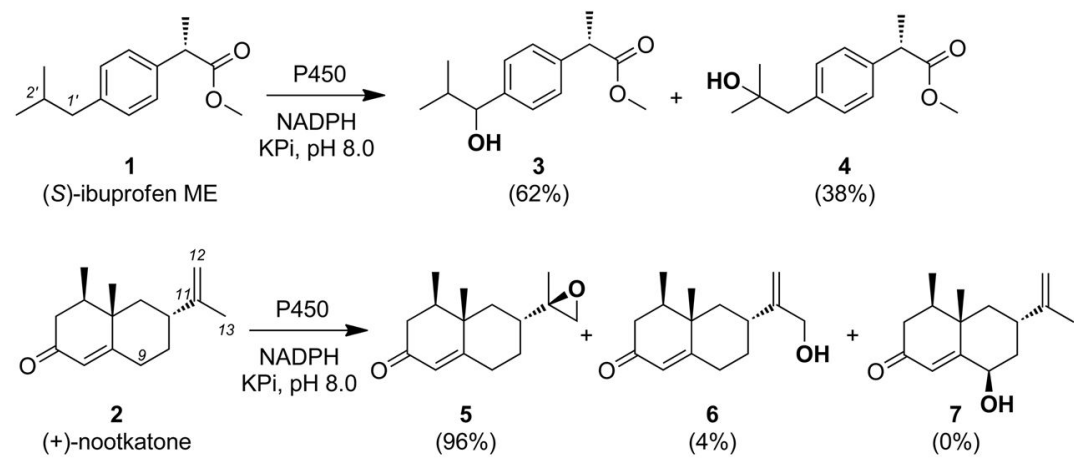

Scheme 1.

Oxidation products obtained from the $\mathrm{P} 450$-catalyzed transformations of $(S)$-ibuprofen methyl ester and (+)-nootkatone investigated in this study. The product distribution of the parent P450 (139-3) is indicated in brackets. 


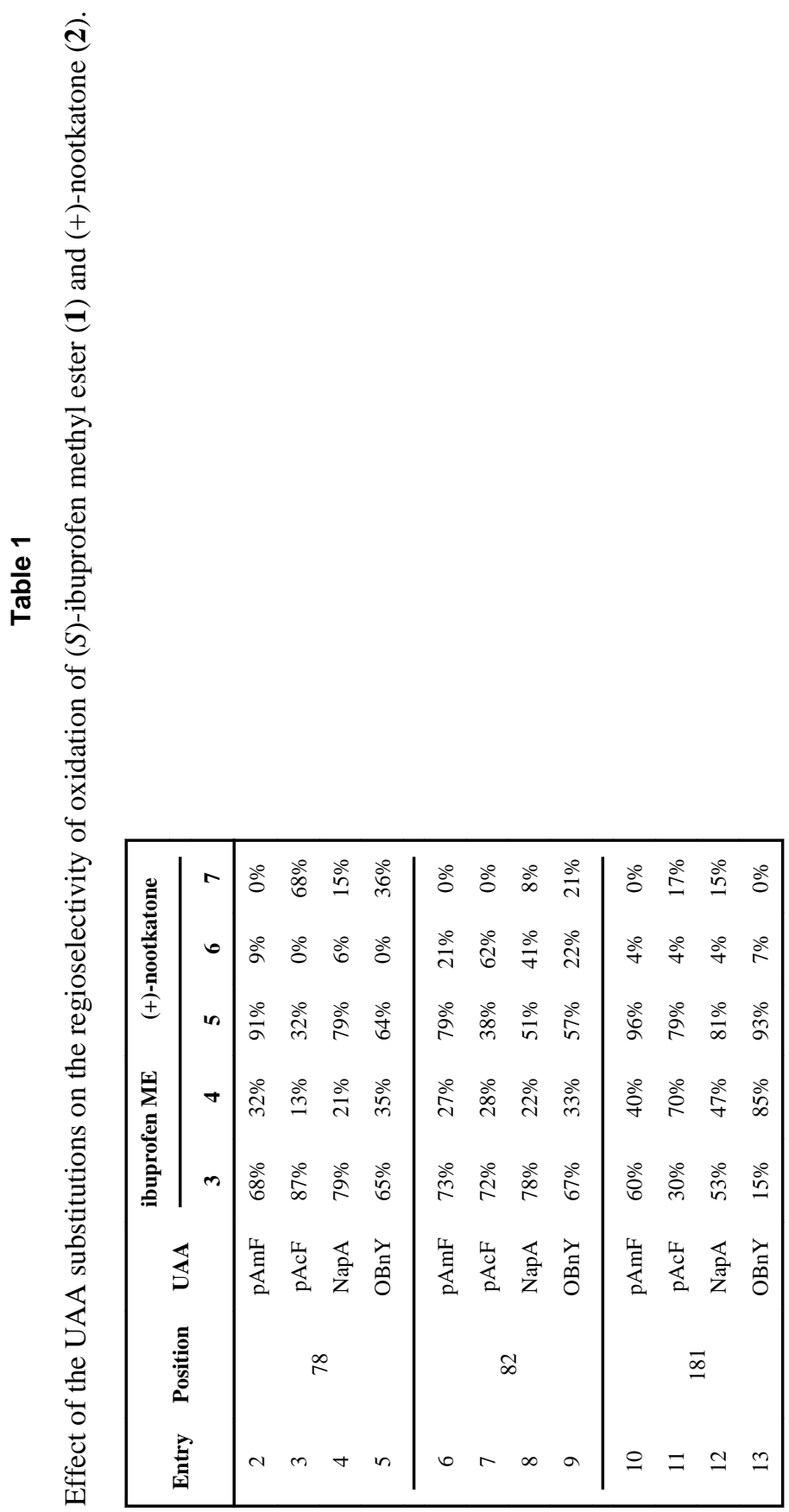


